\title{
Smart Shopping System with RFID Technology Based on Internet of Things
}

\author{
https://doi.org/10.3991/ijim.v14i04.13511 \\ Naseer Ali Hussien ${ }^{\bowtie}$, Saif ali abd alradha alsaidi, Iman Kadhim Ajlan, \\ Wasit University, Wasit, Iraq \\ naseerali@uowasit.edu.iq \\ Mohamed Fazil Mohamed Firdhous \\ University of Moratuwa, Moratuwa, Sri Lanka \\ Haider TH. Salim ALRikabi \\ Wasit University, Wasit, Iraq
}

\begin{abstract}
Internet of Things (IOT) applications represent a new revolution in information technology field. Researchers have predicted that by 2020 , the number of digitally connected devices will exceed 50 billion. However, due to the fact that IOT applications aim to provide the ability for billions of smart devices to connect and interact to each other via the Internet. The misuse of such a standard has been broadly explored in Internet-related investigations. Therefore, a few initiatives have been put forward that employ informal organizations to search for Internet assets, course activity, or choose powerful strategies for substance dissemination. The essential understanding is that this knowledge remains in a persistent locality everywhere around us as a diverse carrier of things or articles - i.e. Radio-Frequency Identification (RFID) sensors, labels, cellular telephones, actuators and more - and one which completes the inclination towards novel ideas, including the ability to submit through one another, as well as contribute through neighbors for the realization of the normal objectives of the shopping situation in the business sector. This paper proposed application for shopping with RFID technology by use the concept of Internet of Things (IOT).
\end{abstract}

Keywords: RFID Innovation, Internet of Things, Future Application, Shopping

\section{Introduction}

The following RFID waves at the time of the shopping process may be external for the domain in the system [1-3]. In the Internet of Things (IOT) the ideal prototype would involve large portions on articles, which cover the system in some sort of structure $[4,5]$. "Radio frequency identification system (RFID) is an automatic technology and aids machines or computers to identify objects, record metadata or control individual target through radio waves. Connecting RFID reader to the terminal of Internet, the readers can identify, track and monitor the objects attached with tags globally, 
automatically, and in real time, if needed" [6]. RFID is one of A wireless communication technology that used for identifying a single object, animal, or a person.

RFID code and RFID reader are two main keys components. It contains a memory which used to store firm data. Radio frequency waves are transmitted by the RFID reader and whenever the tag comes into locality of the reader it is activated. Such an activated tag sends information from its memory to RFID reader in the form of wave.

RFID can be used for smart shopping by attaching each product to A RFID tag. In addition, connecting readings to smart carts and shelves. The system will save the track of all the sold goods and produce a bill depending on this information. All customers will be able to show the purchased items on the LCD screen of the smart shopping cart

Thus, the billing data will be produced pro-actively without any human intervention. The customer has to just pay the amount of billing at the point of sales [7]. The result structure may include administrations, which are wares and conveyed in a manner like conventional items[8]. Distributed computing may give the innovative virtual framework to such useful processing that coordinates observing and stockpiling gadgets, investigation instruments, perception stages and customer conveyance [9, 10]. The payment centered prototype which includes cloud figuring suggestions may enable end-to-end administration providing maintenance for clients and organizations to develop applications [11]. Powerful and sharp integration with the existing systems and connecting careful calculation utilizing the assets of the system is an imperative part of IOT[12]. This will involve developing the locality of the 4G-LTE and Wi-Fi Internet on remote which enable the advancement in the direction of pervasive data, in addition to the correspondence systems. [13-15]. In any case, for the vision of the IOT to effectively extend, this registering ideal model may of necessity go past conventional versatile figuring situations that use PDAs and portables, and develop into joining ordinary existing questions and installing insight into our surroundings[16].

For innovation to vanish of awareness for the clients who shop, the IOT applications include [17-19]:

- A general understanding regarding the context for shopping client machines,

- Programming structural design besides the prevailing correspondence systems to prepare and pass on the logical data applicable for the shopping clients, and

- Investigation tools in the Internet of Things that encourage the shopping clients to have independent and savvy behavior.

- With these three major grounds in the shopping sphere, savvy integration with shopping clients and setting mindful processing for them.

This paper shows the ebb and flow of inclinations towards IOT examination driven by RFID applications for the shopping scenario and the requirements for meeting them within a few interdisciplinary advancements in the shopping setting. 


\section{Related Work}

The key term Internet of Things was originally introduced by Kevin Ashton in 1999 in the production network administration setting [20, 21]. Anyhow, over the last few decades, the meaning of IOT has been expanded to include a wide-ranging variety of uses like social insurance, transport, utilities, etc.[22]. The significance of "Things" has transformed as innovation advanced, the fundamental objective data continues to require the controller of human intervention as it did earlier [23]. The essential growth of the contemporary Internet interested in a Network of interrelated items, includes disinterest, collects facts to begin(detecting) and interfaces the physical world (activation/charge/control), and further uses the present Internet benchmarks to provide access to information examination, exchange, interchanges, and applications[24].

Powered by the commonness of the devices enabled by exposed remote innovations, i.e., Bluetooth, Wi-Fi, radio recurrence ID (RFID), and telephonic information benefits with actuator hubs and inserted sensors, IOT has offered out for earliest stages and is roughly changing the current stationary Internet into an entirely coordinated Future Internet [25]. The Internet has encouraged interconnection among those at an exceptional rules [26]. The next upset will be the interconnection between items to make a brilliant situation[27]. Only 2011, did the numbers of interconnected gadgets in the world overwhelm the genuine number of persons. Today, there are 9 billion gadgets worldwide, which are interconnected and this may be expected to reach 24 billion devices by 2020 . This enhances up to $\$ 1.3$ trillion revenue built-up gate same data versatile system of administrators single-handedly spreading over upright fragments, i.e. well-being, utilities, car and shopper hardware as per the GSMA[18, 28, 29]. A representation of the interconnection of objects is revealed using the IOT, where the request spaces are selected in opinion of the scope for result of the data created. The customers coperangesfrom one individual to nationwide associations nurture to distant getting subjects[30].

Promises accessible by the IOT brand imaginable advancement for massive number of uses, those little portions that are overall available to the public at present[31]. The spaces and the conditions that innovative applications can be expected to improve the environments of our lives will be areas where devices are plentiful in number: at work, when incapacitated, while traveling, at home, at an exercise center when running just like a couple[32]. The present conditions are the ones formerly equipped with things using just prime Val information, with a majority of intervals, having no communication abilities[33]. Giving these items the option to communicate with similar things and to expand that information adage regarding the situation suggests consuming various conditions someplace where a widespread variability of uses will be sent $[34,35]$.This information will be gathered keen on the accompanying spaces (See Figure 1):

- Healthcare domain

- Logistics and Transportation domain

- Social and Personal domain 
- Smart atmosphere (plant, home, office,) domain

Among the possible presentations, this can distinguish between those that are either closely relevant or straight forward to our present existing habits and their cutting edge, that it might just kindness of current situation, and the improvements and/or their community instructions are not organized aimed at their sending (see Figure1)[36]. In the accompanying sub categories it gives survey of the main shortmedium submission period to these classifications and the scope for cutting edge applications[37].

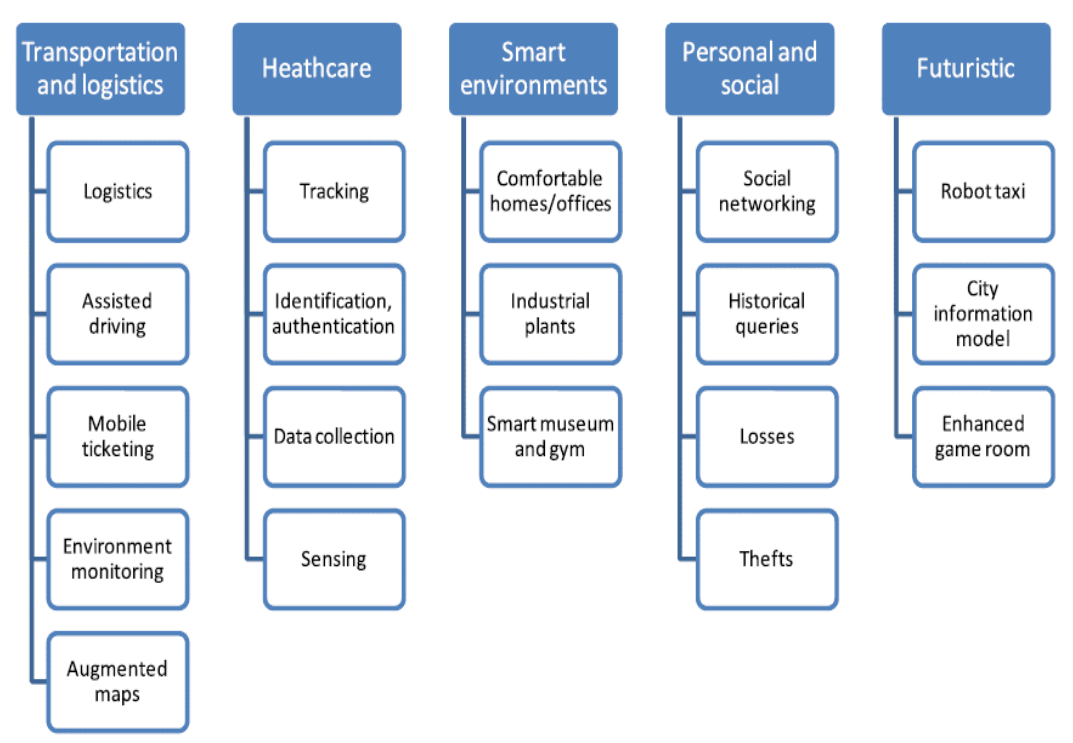

Fig. 1. Applications Domains and Relevant Major Scenarios.

In fact, Krishna et al.,(2008) studied the RFID framework which resulted in a learning that discovered the scope of RFID to peruse even diverse materials and labels (wherever tags are introduced).These are a few reasons why these item materials could not influence the execution of RFID peruses[38, 39]. A few significant studies have been produced which have identified with the present RFID situation (Lanigan et al., 2008; Kulyukin and Kutiyanawala, 2010; Nicholson et al., 2009). In Lanigan et al., (2007) the creators suggested Trinetra, frame work proposed to assist the visually impaired individuals to shop for food, for item pursuit and identification [40-42]. As the outwardly impeded outputs a basic need thing with a convenient scanner tag or RFID peruse, the information examined is sent via Bluetooth to the client's PDA, which checks its store for an item coordinate[43]. If a store miss occurs, the advanced mobile phone will speak through the phone GPRS with the end communication server. If the event of miss with the RFID from the RFID database or an open Universal Product Code (UPC) occurs, that changes over for standardized identification or label into a human-readable item designation (and associated data) and carries the information to the PDA[44]. A locally available content-to-discourse programming in 
advanced mobile phone changes over the showed content into discourse[45]. The benefits of the RFID labels over standardized tags are their reprogram ability, capacity to contain greater item data and capacity to peruse without any observable perusing pathway[46]. The Trinetra framework was effectively tested at the research lab of Carnegie Mellon University's grounds store[47].

Shoptalk is a proposed wearable framework to assist physically disabled customers[48]. The clients acquire speaking guidelines from a connected handheld PC. This information is then passed on to tags situated on the empower route of the racks within the store with help of a Modified Plessey (MSI) scanner. The UPC scanner tags empower item confinement in a store passageway[49]. In the creation form, the framework will unite with the stock control database of the store and gaze upward the item data[50]. Successful trials with physically challenged clients were achieved with in the market[51]. A client assembles a shopping rundown of items with a site and transfers the list to a versatile gadget. Far ahead, the customer gives the output information to the store with a handheld video device[52,53]. This resembles a hand glove for the vibrating engines and the sound fora convenient gadget, which is employed for managing customer requirements [54]. The ability to identify the items on a shopping list of a customer are exhibited from the customer requirement analyses[55].

\subsection{Proposed system}

In this situation, visually impaired individuals shop independently as shown in Figure3. The visually impaired route framework enables them to find their own way in a shop or store. The shopper store's RFID framework utilizes programming to manage the physically disabled individuals in a shopping environment. In fact, RFID-label used route framework as illustrated in [55]. These RFID labels are appropriately connected from end to end of the floor. These label IDs inside the connected phone are equipped with the route, for example, the type of a given cell and the types of neighboring ones as stated in [56]. 


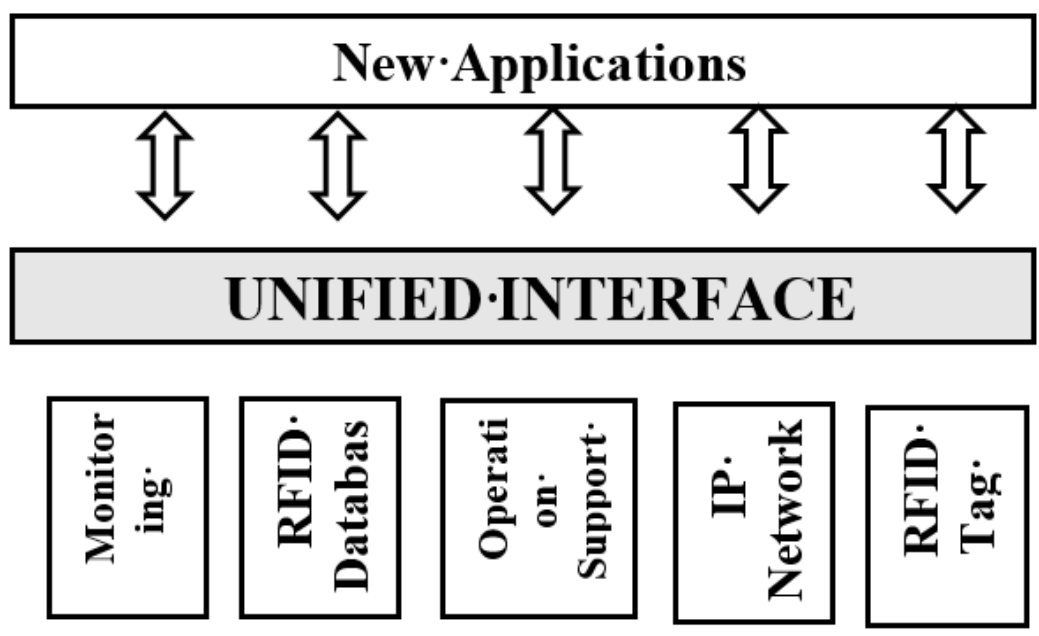

Fig. 2. RFID Unified Interface for Shopping Scenario

The checking station (advanced mobile phone) maintains the association of a Bluetooth with the RFID peruse (keen stick) of the client to stay informed regarding his/her position at whatever time, utilizing the mapping of the label IDs with the route data (as shown in Figure 2). The discourse union and acknowledgment component of the observing position (advanced mobile handset) empowers the physically impaired individual to mention the particular segment of the grocery store or some particular place he/she needs to get the shopping done. These course on take after is gotten using the internet assistance via WLAN associated with the remote server. Using this, the physically disabled can stroll, steering their way using an android application on the phone received by the earphone of the advanced cell and engage in re-creation as vocal sound communications. 


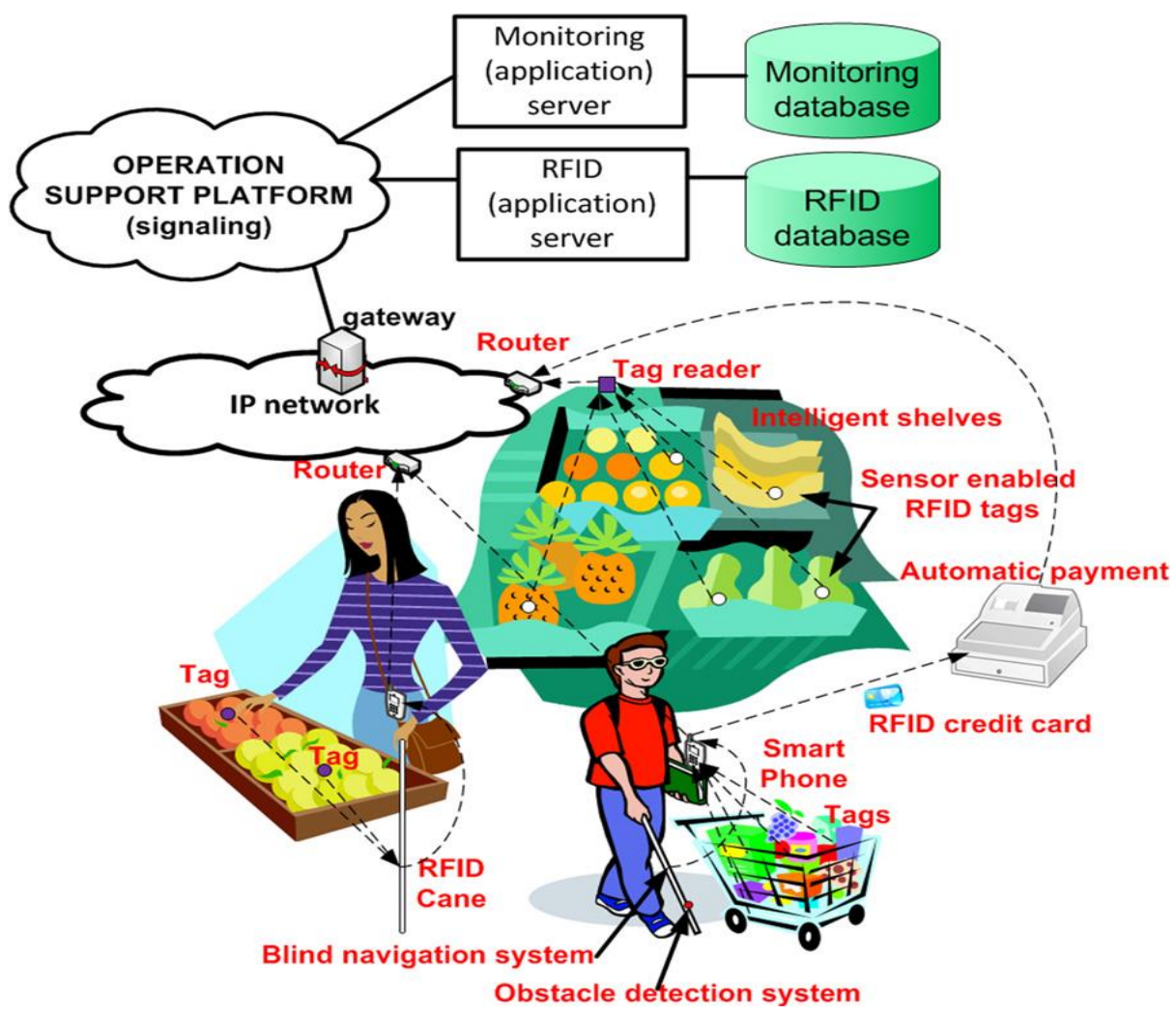

Fig. 3. Future Application Scenario for Shopping Using RFID on IOT

The RFID labels affixed on grocery store items supply expert conduit information, for example, item name, portrayal and cost. Sensor empowered RFID labels provide vital information, for example, temperature or stuns amid transportation. The label peruse (RFID stick) communicates with the label ID information sequence to the checking place that advances for the RFID remote server (as shown in Figure 4). Item data comes back for examining the place from the connected RFID datacenter and returns as vocal sound communications. Extra qualities of the item may include sustenance organization, specific information identified and caloric admission with the client profile, for example, food hypersensitivities and intolerances. Companion assessments regarding the item and examination of the value with comparative items can be received using inter personal organization. 


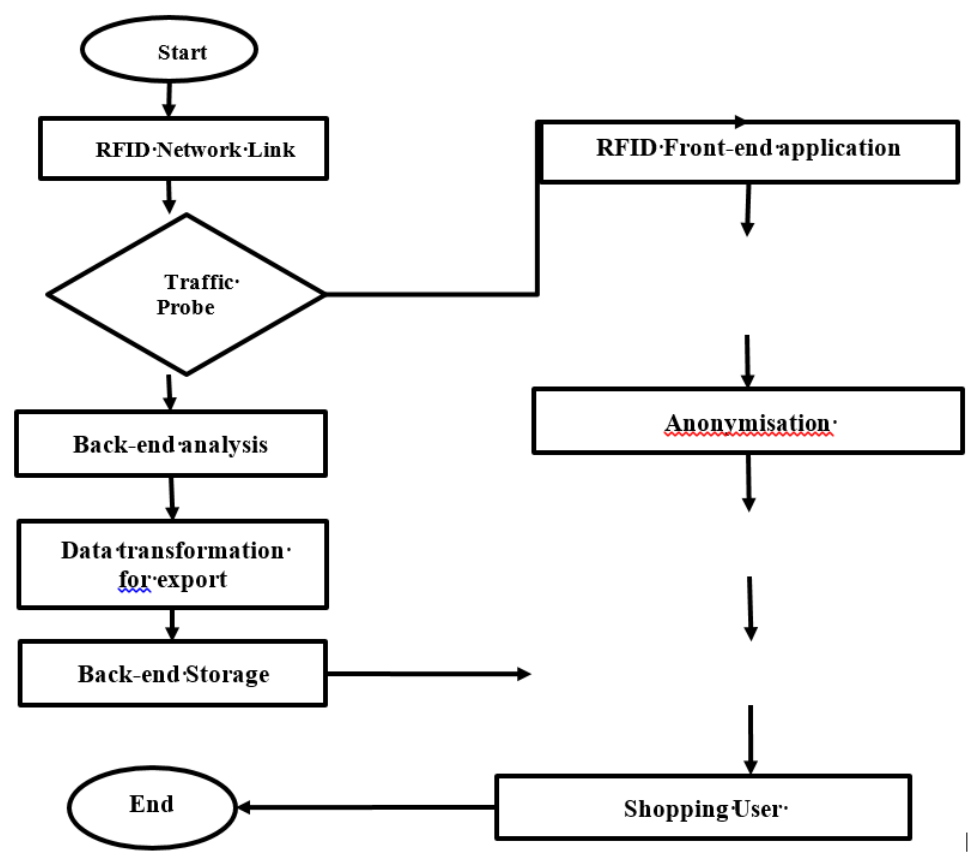

Fig. 4. Process Flow for Shopping Scenario Using RFID

Likewise, programmed installment can be achieved by using the RFID labels. An MSI scanner peruses the IOT enabled things in the truck immediately, adding up to charges of the client's record whenever the shop stock is conformed. The RFID labels charge their cards using a hand-held radio in order to spread the payment information of the individual. Furthermore, occasional insights and reports regarding market shopping will be processed and periodically directed to the checking place computer from the observing remote server.

\section{Conclusion}

The Internet will drastically transform the way human beings live by moving connections among entities at a computer-generated side by side in a limited setting, crossing as of the skilled life to community influences. This kind of IOT could practicably add another dimension to this technique by investing correspondences among extreme substances, thus supporting the vision of "at any-place, any-thing, any-time, any-media" interchanges. The RFID tags can be used by IOT to be regarded as a component of the Internet which can support general bounds that are liable for significantly exclusive use of the Internet in relation to its use today. Indeed, this is a perfect model, ideal for the present Internet that bolsters and fabricates end-to-end interchanges everywhere, and which are currently used for restricting the element to consumption of the present Internet. This opens up the opportunity for making clear the 
use of IOT for shopping, to be partly utilized in the manner of distribution and receiving of data (finance paying for little respect to the end computer which provides the information in recovered or distributed from)along with the RFID labels, information ought to communication and shopping systems infrastructure requirements. In fact, the existing innovations could vary the IOT to encourage the concept of doable shopping not well suited for the versatility and productivity prerequisites of the RFID's label will challenge. This will open up the interest in profitable ventures in shopping using IOT applications, in the recent years inclining of this kind subjects can be an intense powerful variable for shopping correspondence and research can be encouraged for shopping in both academic and mechanical demo labs.

\section{$4 \quad$ References}

[1] S. S. Ganesh, B. Sahithi, S. Akhila, T. J. I. J. o. I. R. i. E. Venumadhav, and Management, "RFID based shopping cart," vol. 2, no. 3, 2015.

[2] M. R. Sawant, K. Krishnan, S. Bhokre, P. J. I. J. o. E. R. Bhosale, and G. Science, "The RFID based smart shopping cart," vol. 3, no. 2, pp. 275-280, 2015.

[3] L. Yan, Y. Zhang, L. T. Yang, and H. Ning, The Internet of things: from RFID to the next-generation pervasive networked systems. Crc Press, 2008. https://doi.org/10.1201/9781420052824

[4] G. J. V. Santucci and C. f. R. t. I. o. Things, "The internet of things: Between the revolution of the internet and the metamorphosis of objects," pp. 11-24, 2010.

[5] H. T. S. ALRikabi, A. H. M. Alaidi, and F. T. Abed, "Attendance System Design and Implementation Based On Radio Frequency Identification (RFID) And Arduino."

[6] H. Sundmaeker, P. Guillemin, P. Friess, and S. J. C. o. E. R. P. o. t. I. o. T. Woelfflé, European Commision, "Vision and challenges for realising the Internet of Things," vol. 3, no. 3, pp. 34-36, 2010.

[7] J. M. Alonso, C. Castiello, and C. Mencar, "The role of interpretable fuzzy systems in designing cognitive cities," in Designing Cognitive Cities: Springer, 2019, pp. 131-152. https://doi.org/10.1007/978-3-030-00317-3_6

[8] R. G. Hussain, M. A. Ghazanfar, M. A. Azam, U. Naeem, and S. U. J. A. I. R. Rehman, "A performance comparison of machine learning classification approaches for robust activity of daily living recognition," vol. 52, no. 1, pp. 357379, 2019. https://doi.org/10.1007/s10462-018-9623-5

[9] J. L. Fortenberry and P. J. J. J. o. A. R. McGoldrick, "Do Billboard Advertisements Drive Customer Retention? Expanding the "AIDA" Model to "AIDAR"," 2019. https://doi.org/10.2501/jar-2019-003

[10] S. Haller, S. Karnouskos, and C. Schroth, "The internet of things in an enterprise context," in Future Internet Symposium, 2008, pp. 14-28: Springer.

[11] R. Ullah, M. A. U. Rehman, and B.-S. J. I. A. Kim, "Design and Implementation of an Open Source Framework and Prototype for Named Data Networking-Based Edge Cloud Computing System," vol. 7, pp. 57741-57759, 2019. https://doi.org/10.1109/access.2019.2914067

[12] S. Tayyaba, S. A. Khan, M. W. Ashraf, and V. E. Balas, "Home Automation Using IOT," in Recent Trends and Advances in Artificial Intelligence and Internet of 
Things: Springer, 2020, pp. 343-388. https://doi.org/10.1007/978-3-030-32644$\underline{9} 31$

[13] N. H. Beebe, "A Complete Bibliography of Publications in the Journal of Network and Computer Applications," 2019.

[14] H. T. Alrikabi, A. H. M. Alaidi, A. S. Abdalrada, and F. T. J. I. J. o. E. T. i. L. Abed, "Analysis the Efficient Energy Prediction for 5G Wireless Communication Technologies," vol. 14, no. 08, pp. 23-37, 2019. https://doi.org/10.3991 lijet.v14i08.10485

[15] L. A. Amaral et al., "eCloudRFID-A mobile software framework architecture for pervasive RFID-based applications," vol. 34, no. 3, pp. 972-979, 2011.

[16] S. M. Stennett and J. W. Talley, "Intelligence situational awareness," ed: Google Patents, 2020.

[17] D. Soni, A. K. Behera, D. Sharma, M. Aslam, and S. Yadav, "A Dielectric Modulated Polarity Controlled Electrically Doped Junctionless TFET Biosensor for IOT Applications," in Smart Systems and IOT: Innovations in Computing: Springer, 2020, pp. 159-168. https://doi.org/10.1007/978-981-13-8406-6 16

[18] H. Alrikabi, A. H. Alaidi, and K. J. I. J. o. I. M. T. Nasser, "The Application of Wireless Communication in IOT for Saving Electrical Energy," vol. 14, no. 01, pp. 152-160, 2020. https://doi.org/10.3991/ijim.v14i01.11538

[19] S. Verma, A. Bhatia, A. Chug, and A. P. Singh, "Recent Advancements in Multimedia Big Data Computing for IOT Applications in Precision Agriculture: Opportunities, Issues, and Challenges," in Multimedia Big Data Computing for IOT Applications: Springer, 2020, pp. 391-416. https://doi.org/10.1007/978-981-13$\underline{8759-3 \quad 15}$

[20] M. B. J. I. J. o. S. SR and R. Publications, "Automatic smart parking system using Internet of Things (IOT)," vol. 5, no. 12, pp. 629-632, 2015.

[21] S. Mahajan, A. Kokane, A. Shewale, M. Shinde, S. J. I. J. o. A. E. R. Ingale, and Science, "Smart Waste Management System using IOT," vol. 4, no. 4, 2017. https://doi.org/10.22161/ijaers.4.4.12

[22] K. Rose, S. Eldridge, and L. J. T. I. S. Chapin, "The internet of things: An overview," vol. 80, 2015.

[23] S. Kuryla, "RPL: IPv6 routing protocol for low power and lossy networks," in Networks and distributed systems seminar, 2010.

[24] R. Sharma, "Evolution in smart city infrastructure with IOT potential applications," in Internet of Things and Big Data Analytics for Smart Generation: Springer, 2019, pp. 153-183. https://doi.org/10.1007/978-3-030-04203-5_8

[25] J. J. Krohn, S. A. Wilson, K. Qian, W. D. Camp, S. Boyapati, and D. Kumar, "Timeout durations for radio frequency identification tags," ed: Google Patents, 2019.

[26] A. Sorescu, R. T. Frambach, J. Singh, A. Rangaswamy, and C. J. J. o. r. Bridges, "Innovations in retail business models," vol. 87, pp. S3-S16, 2011. https://doi.org/10.1016/i.jretai.2011.04.005

[27] T. W. Adorno and M. Horkheimer, Towards a new manifesto. Verso, 2019.

[28] M. C. J. J. o. N. Domingo and C. Applications, "An overview of the Internet of Things for people with disabilities," vol. 35, no. 2, pp. 584-596, 2012. 
[29] C. Perera, M. Barhamgi, A. K. Bandara, M. Ajmal, B. Price, and B. J. I. S. Nuseibeh, "Designing privacy-aware internet of things applications," vol. 512, pp. 238-257, 2020. https://doi.org/10.1016/j.ins.2019.09.061

[30] R. R. Taylor, The intentional relationship: Occupational therapy and use of self. FA Davis, 2020.

[31] G. G. Parker, M. W. Van Alstyne, and S. P. Choudary, Platform Revolution: How Networked Markets Are Transforming the Economy? And How to Make Them Work for You. WW Norton \& Company, 2016.

[32] P. Giner, C. Cetina, J. Fons, and V. J. I. P. C. Pelechano, "Developing mobile workflow support in the internet of things," no. 2, pp. 18-26, 2010. https://doi.org/10.1109/mprv.2010.14

[33] M. Ben-Daya, E. Hassini, and Z. J. I. J. o. P. R. Bahroun, "Internet of things and supply chain management: a literature review," vol. 57, no. 15-16, pp. 4719-4742, 2019. https://doi.org/10.1080/00207543.2017.1402140

[34] B. S. Davie and L. L. Peterson, Computer networks. Morgan kaufmann, 2019.

[35] B. Hengeveld, C. Hummels, K. Overbeeke, R. Voort, H. van Balkom, and J. de Moor, "Tangibles for toddlers learning language," in Proceedings of the 3rd International Conference on Tangible and Embedded Interaction, 2009, pp. 161168. https://doi.org/10.1145/1517664.1517702

[36] A. Choudhuri, J. M. Chatterjee, and S. Garg, "Internet of Things in Healthcare: A Brief Overview," in Internet of Things in Biomedical Engineering: Elsevier, 2019, pp. 131-160. https://doi.org/10.1016/b978-0-12-817356-5.00008-5

[37] K. Silverbrook, P. Lapstun, and J. A. Lapstun, "System for performing data searches on a network," ed: Google Patents, 2010.

[38] M. Kranz, L. Roalter, and F. Michahelles, "Things that twitter: social networks and the internet of things," in What can the Internet of Things do for the Citizen (CIOT) Workshop at The Eighth International Conference on Pervasive Computing (Pervasive 2010), 2010, pp. 1-10. https://doi.org/10.1109/mprv.2010.88

[39] C. P. Chen and C.-Y. J. I. s. Zhang, "Data-intensive applications, challenges, techniques and technologies: A survey on Big Data," vol. 275, pp. 314-347, 2014.

[40] V. Kulyukin and A. J. T. O. R. J. Kutiyanawala, "Accessible shopping systems for blind and visually impaired individuals: Design requirements and the state of the art," vol. 3, no. 1, 2010. https://doi.org/10.2174/1874943701003010158

[41] J. Nicholson, V. Kulyukin, and D. J. T. O. R. J. Coster, "ShopTalk: independent blind shopping through verbal route directions and barcode scans," vol. 2, no. 1, 2009. https://doi.org/10.2174/1874943700902010011

[42] P. De, Y. Liu, and S. K. J. I. T. o. m. C. Das, "An epidemic theoretic framework for vulnerability analysis of broadcast protocols in wireless sensor networks," vol. 8, no. 3, pp. 413-425, 2008. https://doi.org/10.1109/tmc.2008.115

[43] H. Rout, B. K. J. I. J. o. E. Mishra, and C. Engineering, "Pros and cons of cryptography, steganography and perturbation techniques," pp. 76-81, 2014.

[44] D. Rowles, Mobile marketing: how mobile technology is revolutionizing marketing, communications and advertising. Kogan Page Publishers, 2017.

[45] D. J. Howarth, D. R. Howarth, A. J. Norval, and Y. Stavrakakis, Discourse theory and political analysis: Identities, hegemonies and social change. Manchester University Press, 2000. 
[46] G. Hariton, J. Lawford, and H. Palihapitiya, Radio Frequency Identification and Privacy: Shopping Into Surveillance. Public Interest Advocacy Centre, 2006.

[47] B. S. Zor and A. J. M. B. v. T. D. Vuruşkan, "ASSISTIVE TECHNOLOGIES FOR INDIVIDUALS WITH VISUAL IMPAIRMENT: CONTRIBUTION OF DESIGN IN THE FIELD OF CLOTHING," vol. 7, no. 4, pp. 913-925, 2019.

[48] A. Faiola, E. L. Papautsky, and M. J. C. p. i. c. Isola, "Empowering the aging with mobile health: A mhealth framework for supporting sustainable healthy lifestyle behavior," vol. 44, no. 8, pp. 232-266, 2019. https://doi.org/10.1016/ j.cpcardiol.2018.06.003

[49] H. Ren, M. Q.-H. Meng, and X. Chen, "Wireless assistive sensor networks for the deaf," in 2006 IEEE/RSJ International Conference on Intelligent Robots and Systems, 2006, pp. 4804-4808: IEEE. https://doi.org/10.1109/iros.2006.282354

[50] B. Acharya, A. K. Jena, J. M. Chatterjee, R. Kumar, and D.-N. J. I. J. o. K.-B. O. Le, "NoSQL Database Classification: New Era of Databases for Big Data," vol. 9, no. 1, pp. 50-65, 2019. https://doi.org/10.4018/ijkbo.2019010105

[51] J. Allen, A. D. James, P. J. R. Gamlen, and d. Management, "Formal versus informal knowledge networks in R\&D: a case study using social network analysis," vol. 37, no. 3, pp. 179-196, 2007. https://doi.org/10.1111/j.14679310.2007.00468.x

[52] R. Kaplan, "Method and apparatus for transferring or receiving data via the Internet securely," ed: Google Patents, 2006.

[53] H. Satoh, T. Kawabata, and Y. Sankai, "Bathing care assistance with robot suit HAL," in 2009 IEEE International Conference on Robotics and Biomimetics (ROBIO), 2009, pp. 498-503: IEEE. https://doi.org/10.1109/robio.2009.5420697

[54] R. Nanda, IOT and Smart Cities: Your smart city planning guide. BPB Publications, 2019.

[55] Z. Shelby, K. Hartke, C. Bormann, and B. Frank, "The constrained application protocol (CoAP)," 2014. https://doi.org/10.17487/rfc7252

[56] C. Taehoon and S. Jie, "Mobile terminal for sharing image with nearby blackbox device and method for controlling the same," ed: Google Patents, 2019.

\section{Authors}

Naseer Ali Hussien is presently an Associate Professor and the Assistant Dean for Scientific Affairs of the Education College for Pure Sciences, Wasit University in Al Kut, Wasit, Iraq. He received his B.Sc. degree in Computer Science in 2000 from the Baghdad University in Baghdad, Iraq, his M.Sc. degree in Computer Science focusing on Computer Network and Communications from Hamdard University, Delhi, India in 2008 and the PhD in Information Technology from University Utara Malaysia in 2013. His current research interests include network performance monitoring and analysis, wireless and mobile ad hoc networks, network protocol engineering, network simulation, network applications, smart cities, Internet of Things (IoT) and Internet of Vehicle (IoV). Al Kut city - Hay ALRabee, Wasit, Iraq. Contact:+9647711021768. E-mail:- naseerali@uowasit.edu.iq 
Saif ali abd alradha alsaidi is a Lecturer Computer science department at College of Education for Pure Science, Wasit university, Al Kut city - Hay ALRabee, Wasit, Iraq.

Iman Kadhim Ajlan is the Faculty of Medicine College atWasit University Email:- imykazem73@gmail.com.

Dr. Mohamed Fazil Mohamed Firdhous is a Senior Lecturer attached to the Department of Information Technology of the Faculty of Information Technology, University of Moratwua, Sri Lanka. He is engaged in undergraduate and postgraduate teaching along with cutting edge research in the areas of trust and trust management in cloud computing, Internet of Things, mobile adhoc networks, vehicular networks, computer security, environment monitoring, intelligent transport systems and rural ICT development. He has teaching, research and industry experience in many countries including Sri Lanka, Singapore, United States of America and Malaysia. In addition to his teaching and research activities, he is a highly sought after ICT consultant to the government and private institutions in Sri Lanka.

Haider Th. Salim ALRikabi is presently one of the Faculty College of Engineering, Electrical Engineering Department, Wasit University in Al Kut, Wasit, Iraq. He received his B.Sc. degree in Electrical Engineering in 2006 from the Al Mustansiriya University in Baghdad, Iraq. his M.Sc. degree in Electrical Engineering focusing on Communications Systems from California state university/Fullerton, USA in 2014 .His current research interests include Communications systems with mobile generation, Control systems, intelligent technologies, smart cities, and Internet of Things (IoT) . Al Kut city - Hay ALRabee, Wasit, Iraq. Contact: - +9647732212637. Email:- hdhiyab@uowasit.edu.iq. The number of articles in national databases - 8. The number of articles in international databases -8 .

Article submitted 2019-07-24. Resubmitted 2019-08-27. Final acceptance 2019-08-29. Final version published as submitted by the authors. 